

\section{About the Project}

The Guidelines for Home Energy Professionals is a collaboration between the U.S. Department of Energy (DOE) and a wide range of home energy performance industry professionals. The Guidelines project, managed by the National Renewable Energy Laboratory (NREL) for DOE, addresses the need for a highly-skilled weatherization workforce equipped to complete consistent, high-quality home energy upgrades for single-family (SF) homes, multifamily (MF) homes, and manufactured housing (MH). In doing so, it helps increase energy efficiency,

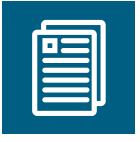

\section{Define Quality Work: Standard Work Specifications (SWS) for Home Energy Upgrades}

- Defining Work as a First Step. The first step in the Guidelines project was to develop Standard Work Specifications reflecting a whole-house approach to energy-efficiency installations.

- Filling a Performance Void with SWS. Prior to the SWS, there was no consistent resource that identified the expected outcomes for individual retrofit measures performed during an energy efficiency upgrade.

- Drawing Upon Years of Experience. The SWS synthesize more than 30 years of Weatherization Assistance Program (WAP) building science expertise within the WAP and the broader home performance industry. The SWS combine original content and relevant codes and standards to identify desired outcomes of quality home energy upgrades.

- Engaging Hundreds of Industry Leaders. The project engaged more than 400 subject matter experts including weatherization professionals, industry technical leaders, and other highly qualified individuals to develop the SWS. During this process, more than 2,000 public comments regarding the SWS were reviewed.

- Providing an Industry Baseline. The SWS serve as a universal resource for the home energy upgrade industry, giving residential contractors, utilities, homeowners, investors, and others a baseline for quality in residential energy upgrades.

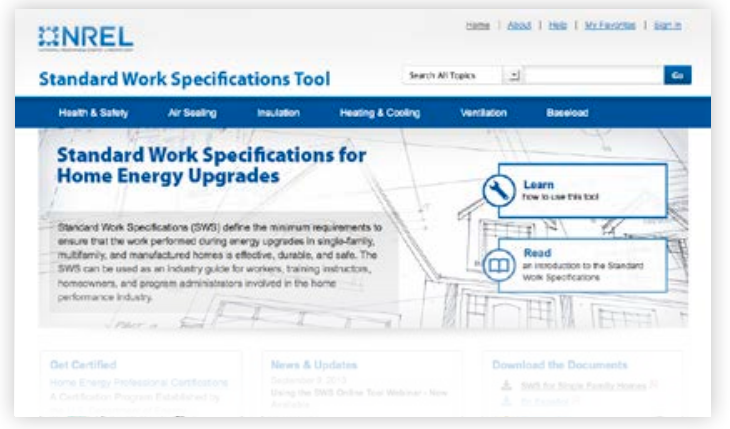

The SWS are available via a dynamic online tool that makes work easier for the weatherization and home performance industry. SWS content is searchable (find the topics and specifications you need), interactive (save custom work plans that facilitate the development of scopes of work and quality control checklists) and accessible to thirdparty organizations via an Application Programming Interface (API).

\section{Timeline of Key Milestones and Events}

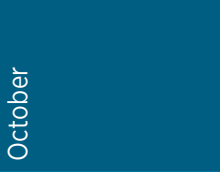

Recovery

through

Retrofit

Report

Released
- Training and Technical Assistance Plan Completed

- NREL

Commissioned

to Develop

SWS, JTAs, and

Certifications

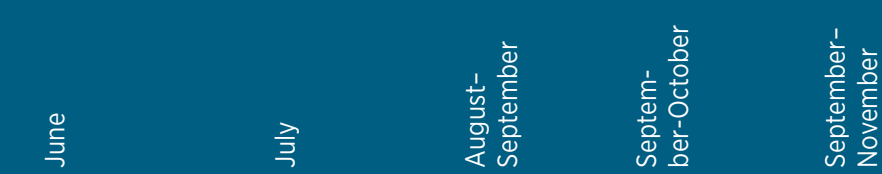

SWS SF

Industry

Meeting: 40

Participants
- JTA Focus

Group

Meetings

- SWS SF

Technical

Review

Committee

Meeting in

Golden, Colorado
SWS SF

Industry

Technical

Review: 156

Participants
JTA Validation Study Survey: 400 Energy Auditors, 150 Quality Control Inspectors, 115 Crew

SWS SF

Federal

Agency

Review
Retrofit Installer

Participants

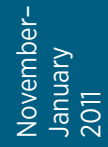

SWS SF

Public Review:

300

participants;

1,200

Comments 


\title{
Guidelines for Home Energy Professionals Project
}

\author{
The resources developed through the Guidelines project are aimed at creating \\ a robust, effective, and quality-driven home energy upgrade industry.
}

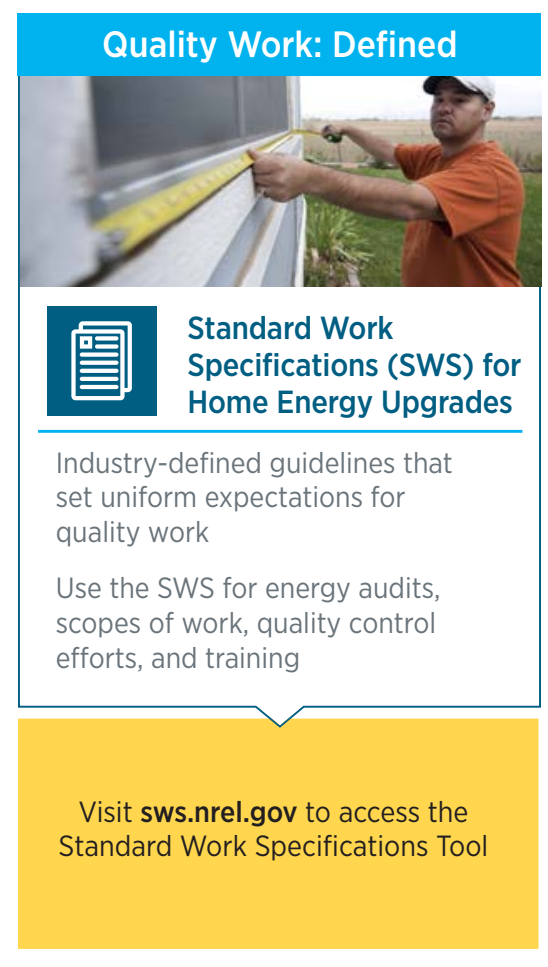

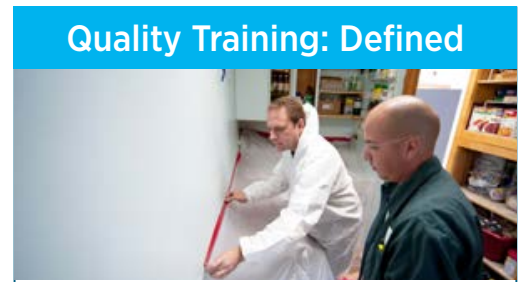

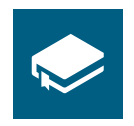

\section{Accredited}

Training

Third-party verified coursework based on industry-developed Job Task Analyses (JTAs) that promote consistency and confidence

Train your workers to deliver the quality work defined in the SWS

Visit eere.energy.gov/wip/ guidelines.html to learn more about Interstate Renewable Energy (IREC) training program accreditation
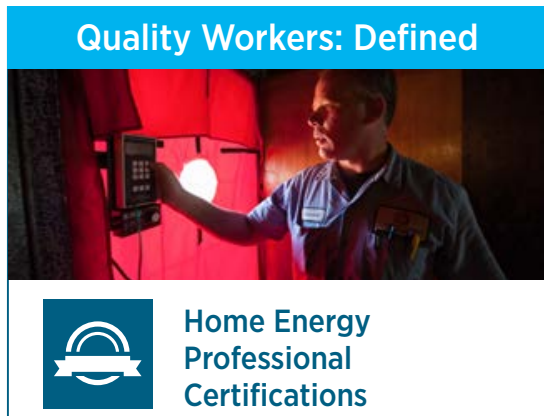

Competency-based certifications that raise the bar by proving worker has experience, education, and training

Certify your workers to increase profits and reduce costs by delivering quality work by competent workers

Visit bpi.org to get certified as a Home Energy Professional-Certifications available for Retrofit Installer Technician, Crew Leader, Energy Audit, Quality Control Inspector

\section{Standardized residential energy upgrade industry and a skilled and credentialed workforce}

Employers and Contractors: Find, hire, and retain committed and competent employees. Reduce callbacks and overall liability.

Home Energy Workers: Enjoy increased flexibility and distinction, and find work with employers that value nationally recognized, transferrable Home Energy Professional Certifications.

Homeowners and Consumers: Experience increased confidence and satisfaction, knowing that your home energy upgrade team is certified and delivering quality work as defined through standard work specifications.

Training Centers: Streamline weatherization training curricula and course materials using industry-defined JTAs.

Utilities and Efficiency Program Administrators: Cut program costs, improve service delivery, reduce callbacks and installation errors, and lessen liability by delivering quality work from an improved workforce.
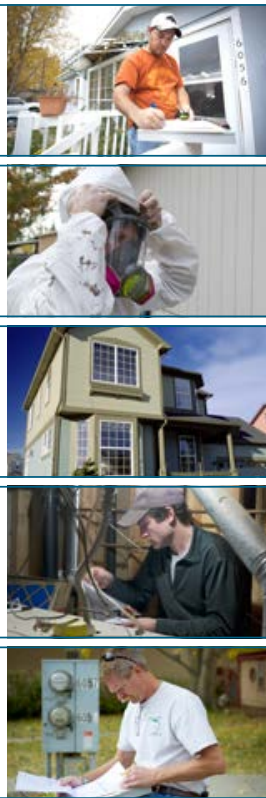


\section{About the DOE Weatherization Assistance Program}

During the past 33 years, the Department of Energy's Weatherization Assistance Program (WAP) has provided weatherization services to more than 6.4 million low-income households. Families receiving weatherization services see their annual energy bills reduced, along with improved comfort, health, and safety. Because the energy improvements that make up weatherization services are long lived, the savings add up over time to generate substantial benefits to weatherization recipients, their communities, and the nation as a whole. The WAP represents the single largest energy efficiency retrofit workforce in the nation. Its decades of experience and leadership make it the ideal organization to develop technical tools and resources to benefit the entire industry.

\section{Guidelines Project Partnering Organizations}

The following organizations contributed to the Guidelines for Home Energy Professionals project:

- Advanced Energy

- Association for Energy Affordability

- Building Performance Institute

- Interstate Renewable Energy Council

- Nahan Communications

- National Renewable Energy Laboratory

- Pacific Northwest National Laboratory

- Professional Testing, Inc.

- U.S. Department of Energy Building Technologies Office

- U.S. Department of Energy Weatherization and Intergovernmental Program

\section{Additional Resources}

SWS Online Tool: https://sws.nrel.gov/

Single-Family JTAs:

- Retrofit Installer/Technician: www.wip.energy.gov/pdfs/retrofit_installer_jta_04112012.pdf

- Crew Leader: www.wip.energy.gov/pdfs/51673.pdf

- Energy Auditor: www.wip.energy.gov/pdfs/51672.pdf

- Quality Control Inspector: www.wip.energy.gov/pdfs/51670.pdf

Multifamily JTAs:

- Retrofit Project Manager: www.nrel.gov/docs/fy14osti/60446.pdf

- Energy Auditor: www.nrel.gov/docs/fy14osti/60447.pdf

- Building Operator: www.nrel.gov/docs/fy14osti/60536.pdf

- Quality Control Inspector: www.nrel.gov/docs/fy14osti/60537.pdf

WIP Website: www.wip.energy.gov

Front page photos by Dennis Schroeder (top, left to right): NREL 18029; NREL 18024; NREL 17964. Pages 3 and 4 (top): Dennis Schroeder, NREL 17959; iStock 8460535; iStock 5035981; iStock 15671548; Dennis Schroeder, NREL 17955. Page 5 (top to bottom): Dennis Schroeder, NREL 18035; Dennis Schroeder, NREL 17958; Dennis Schroeder, NREL 28603; Dennis Schroeder, NREL 18036; Dennis Schroeder, NREL 18015; Warren Gretz, NREL 08742; Dennis Schroeder, NREL 18019; Dennis Schroeder, NREL 18022 